\title{
ON THE IMPACT OF VALLEY/RIDGE THERMALLY INDUCED CIRCULATIONS ON REGIONAL POLLUTANT TRANSPORT
}

\author{
M. Segal, C.-H. Yu, R. W. Arritt and R. A. Pielke \\ Department of Atmospheric Science, Colorado State University, Fort Collins, CO 80523, U.S.A.
}

(First received 12 January 1987 and in final form 13 August 1987)

\begin{abstract}
The impact of thermally induced valley/ridge circulations on the regional-scale transport of pollutants is examined using a modeling approach. The approach consists of applying a numerical meteorological model which provides the wind and turbulence fields used as input to a Lagrangian dispersion model. A variety of generic simulations were performed. Results indicate a significant effect of the induced local flows and the thermal stratification on the regional-scale transport. Both the time of the day in which the cross valley/ridge transport occurs and the season of the year are found to be crucial in determining the magnitude and form of the alterations. Conceptual generalizations of the model results are presented.
\end{abstract}

Key word index: Thermally-induced circulations, local circulations and their effect on regional transport, numerical model transport evaluations, dispersion modeling, mesoscale thermally forced circulations and their effect on regional transport.

\section{INTRODUCTION}

During the past two decades, interest in regional-scale (i.e. from $\sim 200$ to $\sim 2000 \mathrm{~km}$ ) transport of polluted air masses has continuously increased (e.g. Eliassen, 1980; Bhumralkar and Teasley, 1984). This interest has been motivated mostly by concerns such as acid deposition and visibility impairment from distant sources. Evaluations of the regional transport of pollutants are usually done by means of trajectory analysis (e.g. Wolff et al., 1977; Haagenson and Shapiro, 1979; Heffter, 1980; Henmi and Bresch, 1985; Samson, 1980; Artz et al., 1985 among others). Wind data for the trajectory analyses are usually provided directly by the synoptic meteorological radiosonde network or more recently by numerical models (e.g. Warner et al., 1983). However, because of the horizontal resolution of this network $(\sim 300$ to $\sim 500 \mathrm{~km})$, it is incapable of resolving the impact of mesoscale systems such as valley/ridge thermally induced flows which are generally of a horizontal scale less than $200 \mathrm{~km}$. Additionally, the temporal resolution of observational synoptic networks (typically $12 \mathrm{~h}$ ) is comparable to the lifetime of these mesoscale systems; thus, even the temporal variations in the mesoscale induced flows cannot be adequately sampled. The regional numerical models generally have a grid spacing in the range of $25-100 \mathrm{~km}$, so only atmospheric features larger than around $100-400 \mathrm{~km}$ can be resolved (assuming that at least four grid intervals are needed to resolve the feature).

The mesoscale systems involved with valley/ridge thermal forcing are anticipated to produce major alterations of the regional pollution transport. They are widespread in nature with typical examples including geographical locations such as the rugged terrain of the Colorado River basin, the Appalachians ridge-valley region, and the Rhine valley in Germany, among others.

The present study is oriented toward an illustration and evaluation of the impact of thermally induced valley/ridge circulations on regional transport. For this purpose several generic numerical mesoscale model simulations were carried out while considering regional transport across an elongated valley/ridge region. Refined horizontal and vertical grid resolutions were adopted in order to adequately resolve the meteorological fields induced by these terrain features. The numerical model provides the meteorological wind and turbulence fields used as input to a Lagrangian dispersion scheme (as outlined in section 2). Adopting these modeling tools, pollutant volumes represented by fields of particles were followed as they crossed the terrain. For these experiments, each assumed volume consisted of a dense array of particles initially located on the boundary of the simulated domain with a horizontal extent of $15 \mathrm{~km}$ and a depth of several hundred meters. Such volumes were released at different hours of the day, for summer and winter conditions. Using the discrete volume releases it is possible to infer the bchavior of continuous transport which can be viewed as an ensemble of such discrete masses. Results of the model simulations are given in section 3 , while in section 4 a conceptual evaluation for the generalized phenomenon is outlined.

\section{MODELING ASPECTS}

\subsection{Numerical mesoscale meteorological model}

The formulation of the numerical mesoscale model used in the present study is given in detail in Pielke 
(1974), Mahrer and Pielke (1977) and McNider and Pielke (1981), and summarized in Pielke (1984). It has been validated successfully in studies of mountain-valley thermally induced flows such as those discussed in the current paper (e.g. Segal et al., 1982; McNider and Pielke, 1984; Abbs, 1986, among others). Since the present study oricntation is illustrative, the model was applied along a simplified $2-\mathrm{D}$ valley and ridge terrain as shown in the figures in section 3 , while assuming a steady synoptic environment and clear-sky conditions. Table 1 provides pertinent input parameters as well as initial conditions for the meteorological model used in the simulations. The model simulations commenced around sunset. The initial potential temperature and specific humidity stated in Table 1 are assumed to be horizontally uniform over the domain of the simulation. The initial wind within the boundary layer is derived by an Ekman solution. Zero gradient boundary conditions are imposed for the prognostic variables at the lateral boundaries.

\subsection{Transport/dispersion model}

A Lagrangian approach which uses the wind and turbulence fields computed by the meteorological model is applied to evaluate the transport and dispersion of pollutants under the coupling of synoptic and thermally forced mountain-valley flows. The Lagrangian approach is based on the formulation given in McNider (1981), and is described also in Pielke et al. (1983) with additional refinements as reported in
Arritt (1985). Validation of the Lagrangian model reported in McNider (1981) and McNider et al. (1988) documented its realistic performance.

The Lagrangian scheme consists of a large number of particles representing a pollutant air mass, which are advected and diffused laterally and vertically, changing their locations, within time interval $\Delta t$, according to the following formulation:

$$
x_{i}(t+\Delta t)=x_{i}(t)+\Delta t\left[u_{i}(t)+u_{i}^{\prime}(t)\right] \quad(i-1,2,3),
$$

where

$\left(x_{1}, x_{2}, x_{3}\right)=(x, y, z)$ and $\left(u_{1}, u_{2}, u_{3}\right)=(u, v, w)$.

$\bar{u}_{i}$ is the explicitly resolvable $i$ th velocity component as predicted by the mesoscale model $\left(\bar{u}_{i}\right.$ $=u_{o_{1}}+u_{i}^{\prime}$, where $u_{o_{i}}$ is a synoptic wind component and $u_{i}^{\prime}$ the perturbation due to a mesoscale forcing), and

$u_{i}^{\prime \prime}$ is the $i$ th turbulent velocity component. computed using a Markov process:

$$
\begin{aligned}
u_{i}^{\prime \prime}(t+\Delta t)= & R_{\mathrm{L}, i} u_{i}^{\prime \prime}(t)+\left[1-R_{\mathrm{L}, i}^{2}\right]^{1 / 2} u_{i}^{\prime \prime \prime}(t) \\
& +\partial_{i 3}\left[1-R_{\mathrm{L}, 3}\right] w_{\mathrm{d}} .
\end{aligned}
$$

in which

$R_{\mathrm{L}, i}$ is the Lagrangian autocorrelation in the $i$ th direction which is parameterized here as

$$
R_{\mathrm{L}, i}=\exp \left(-\Delta t / T_{\mathrm{L}, i}\right)
$$

\begin{tabular}{|c|c|}
\hline Winter & Summer \\
\hline \multicolumn{2}{|c|}{ Input parameters } \\
\hline Latitude $-37^{\circ}$ & Latitude $-37^{\circ}$ \\
\hline $\begin{array}{l}21 \text { December solar radiation } \\
\text { conditions }\end{array}$ & $\begin{array}{l}10 \text { July solar radiation } \\
\text { conditions }\end{array}$ \\
\hline $\begin{array}{l}\text { simulation start } 1700 \text { LST } \\
\text { ( sunset) }\end{array}$ & $\begin{array}{l}\text { simulation start } 2100 \text { LST } \\
(\sim \text { sunset })\end{array}$ \\
\hline $\begin{array}{l}\text { horizontal grid resolution }-5 \mathrm{~km} \\
\text { meteorological model time step }-60 \mathrm{~s}\end{array}$ & $\begin{array}{l}\text { horizontal grid resolution }-5 \mathrm{~km} \\
\text { meteorological model time step- }-60 \mathrm{~s}\end{array}$ \\
\hline Lagrangian model time step $-20 \mathrm{~s}$ & Lagrangian model time step $20 \mathrm{~s}$ \\
\hline \multicolumn{2}{|c|}{ Initial conditions } \\
\hline $\begin{array}{l}U_{\mathrm{g}} \text {-synoptic wind speed } 2.5 \mathrm{~ms}^{-1} \\
\text { (cross valley/ridge) } \\
\text { surface pressure } 1000 \mathrm{mb} \\
\text { surface temperature } 275 \mathrm{~K} \\
\text { potential temperature lapse: }\end{array}$ & $\begin{array}{l}U_{\mathrm{g}} \text {-synoptic wind speed } 2.5 \mathrm{~m} \mathrm{~s}^{-1} \\
\text { (cross valley/ridge) } \\
\text { surface pressure } 1000 \mathrm{mb} \\
\text { surface temperature } 298 \mathrm{~K} \\
\text { potential temperature lapse: }\end{array}$ \\
\hline$z<150 \mathrm{~m}: \frac{\partial \theta}{\partial z}=0 \mathrm{~K} / 1000 \mathrm{~m}$ & $z<350 \mathrm{~m} ; \frac{\partial \theta}{\partial z}=0 \mathrm{~K} / 1000 \mathrm{~m}$ \\
\hline $150 \leqslant z<900 \mathrm{~m} ; \frac{\partial \theta}{\partial z}=10 \mathrm{~K} / 1000 \mathrm{~m}$ & $350 \leqslant z<2450 \mathrm{~m} ; \frac{\partial \theta}{\partial z}=2 \mathrm{~K} / 1000 \mathrm{~m}$ \\
\hline $900 \leqslant z<5000 \mathrm{~m} ; \frac{\partial \theta}{\partial z}=4 \mathrm{~K} / 1000 \mathrm{~m}$ & $2450 \leqslant z<9600 \mathrm{~m} ; \frac{\partial \theta}{\partial z}=4 \mathrm{~K} / 1000 \mathrm{~m}$ \\
\hline $\begin{array}{l}\text { surface specific humidity } 4 \mathrm{~g} / \mathrm{kg} \\
\text { number of vertical levels- }-26\end{array}$ & $\begin{array}{l}\text { surface specific moisture } 5 \mathrm{~g} / \mathrm{kg} \\
\text { number of vertical levels }-26\end{array}$ \\
\hline
\end{tabular}

$T_{\mathrm{L}: i}$ is the Lagrangian time scale in the $i$ th direction,

Table 1. Specification of model input parameters for the winter and summer cases simulations 
and $u_{i}^{\prime \prime \prime}(t)$ is a random velocity component given by

$$
u_{i}^{\prime \prime \prime}(t)=r \sigma_{i}
$$

where

$r$ is a normal random variate with zero mean and unit variance, and $\sigma_{i}$ is the standard deviation of the $i$ th subgrid-scale velocity component

$\delta_{i 3}$ is the delta of Kronecker, and

$w_{\mathrm{d}}$ is the drift velocity correction (Legg and Raupach, 1982) given by

$$
w_{\mathrm{d}}=T_{\mathrm{L} 3} \frac{\partial}{\partial x_{3}}\left(\sigma_{3}^{2}\right)
$$

Information needed to obtain $R_{\mathrm{L}_{i},}, T_{\mathrm{L}_{i}}$ and $\sigma_{i}$ is obtained from the mesoscale meteorological model predictions following the parameterizations suggested by Kaimal et al. (1976), Panofsky et al. (1977) and Blackadar (1978). Detailed description of the Lagrangian module is given in McNider et al. (1980) and McNider (1981). The particles are chemically, radiatively and buoyantly passive. Particles contacting the surface are reflected.

In the present study a volume of particles is assumed to be located on the upwind side of a valley/ridge region, representing a fraction of a larger polluted air mass which is transported by the synoptic flow toward that terrain. The number of particles ( 324 per volume) was specified to ensure, in general, a statistically meaningful representation of the dispersion characteristics. The particle mass consists initially of three stratified layers differentiated graphically: the bottom layer, $\alpha$; the middle layer, $\beta$; the upper layer, $\gamma$ (as indicated on the figures). The graphical differentiation of the pollutant volume into three layers enabled resolving specific effects of the local circulations on the transports. As the particles are transported toward the valley-ridge region, they are dispersed by: (a) differential horizontal transport from the coupled synoptic and valley/ridge horizontal flows, (b) differential vertical transport from the mesoscale generated vertical velocities (the synoptic scale flow was assumed in these experiments to have no vertical motion), and (c) diffusion due to turbulence (the turbulence intensity, in a given layer, which is related to influences such as the thermal stability, the wind shear, and the depth of the boundary layer).

\section{RESULTS}

\subsection{Meteorological fields}

The valley/ridge terrain circulations were simulated for mid-latitude winter and summer cases. The valley and the ridge generic cases have a depth and a height of $800 \mathrm{~m}$, respectively, with a slope steepness of $1 / 100$. The meteorological model simulations began at sunset and continued for $36 \mathrm{~h}$. Selective illustrations of the predicted wind fields and thermal structure are provided in this subsection.

\subsection{Transport patterns}

In order to examine the influence of the thermallyforced flow on dispersion, the pollutant mass was followed for about $24 \mathrm{~h}$. Meteorological data used to obtain the individual particle movement were obtained from the summer and winter meteorological simulations, according to the formulation presented in section 2.2. The pollutant mass, as represented initially by three stratified layers of pollution, was input at different times of the day enabling a projection as to the diurnal impact of flow and turbulence on a continuous transport of a polluted air mass over such terrain. The initial height of the pollutant layers corresponds to a relatively shallow planetary boundary layer (PBL) situation reflecting adverse regional air quality conditions. Table 2 provides information relating to the various cases considered in the following result description.

\subsection{Meteorological fields-valley case}

a. Winter case. Examples of the nocturnal meteorological fields as computed at 0\$00 LST (reflecting the peak of the nocturnal development for the first night) are presented in Fig. 1. The assumed synoptic flow is $2.5 \mathrm{~m} \mathrm{~s}^{-1}$ directed from left to right in the figures (i.e. west-east). In Fig. la the cross valley component of the wind is presented, and except for the shallow drainage flows along the slopes and their return circulations, above the valley the synoptic flow is almost undisturbed. The nocturnal downward vertical velocities along the valley slopes associated with the shallow drainage are noticeable (Fig. 1a, dashed contours). In the valley center, the horizontal convergence of the drainage flows leads to upward vertical velocities. The nocturnal surface inversion is relatively shallow, deepening somewhat at the valley bottom as evident in the potential temperature illustration (Fig. 1e). The potential temperature structure above the valley top is only slightly perturbed from its initial synoptic profile.

The daytime meteorological fields are presented for 1400 LST illustrating a relatively shallow upslope flow layer with wind speeds not exceeding $3 \mathrm{~m} \mathrm{~s}^{-1}$ (Fig. 1b).

Table 2. Description of the simulated transport cases according to hour of particles release, season and terrain specification

\begin{tabular}{llclc}
$\begin{array}{l}\text { Case } \\
\text { No. }\end{array}$ & Season & $\begin{array}{c}\text { Release } \\
\text { hour (LST) }\end{array}$ & $\begin{array}{c}\text { Terrain } \\
\text { characteristics }\end{array}$ & Fig. No. \\
\hline 1 & winter & 0500 & valley & 3 \\
2 & winter & 2100 & valley & 4 \\
3 & summer & 0500 & valley & 5 \\
4 & summer & 2100 & valley & 6 \\
5 & winter & 0500 & ridge & 9 \\
6 & winter & 2100 & ridge & 10 \\
7 & summer & 0500 & ridge & 11 \\
8 & summer & 2100 & ridge & 12 \\
\hline
\end{tabular}



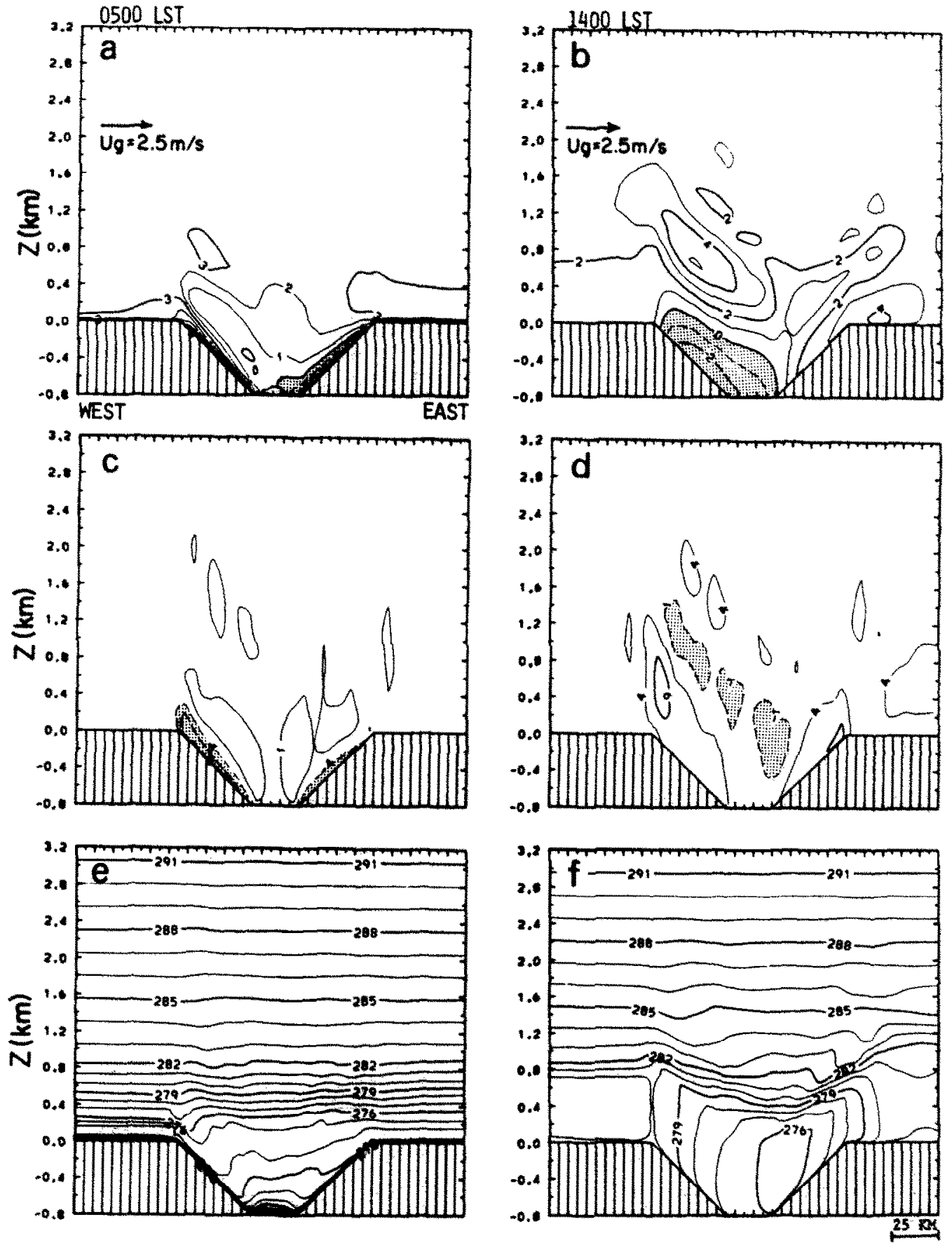

Fig. 1. Representative meteorological fields for the cross-valley transport cases (westerly synoptic fow) for nighttime ( 0500 LST), and for daytime (1400 LST), winter case; (a) and (b) $u$ component of the wind (cross valley) given in $\mathrm{m} \mathrm{s}^{-1}$; dashed contours (shaded) indicate negative values of $u$ (i.e. easterly flow); (c) and (d) vertical velocities given in $\mathrm{cm} \mathrm{s}^{-1}$; dashed contours (shaded) indicate negative values of vertical velocities (i.e. subsidence); (e) and (f) potential temperature (K).

Intensification of the synoptic flow above the western slope had resulted due to the blocking effect of the thermally induced flow, and resulted in a flow with a peak value of $5 \mathrm{~ms}^{-1}$. Upward vertical velocities involved with the thermal slope circulations and the blocking along the western slope are relatively weak (Fig. 1d). Since surface sensible heat fiuxes are relatively low during this season of the year, the development of the daytime PBL is limited generally to less than $1 \mathrm{~km}$, as evident in the potential temperature structure (Fig. 1f). Note that the PBL (i.e. mixing depth) is associated with nearly constant potential temperature with height, indicating neutral thermal stratification.

b. Summer case. Figures $2 \mathrm{a}$ and $2 \mathrm{c}$ present the 0500 

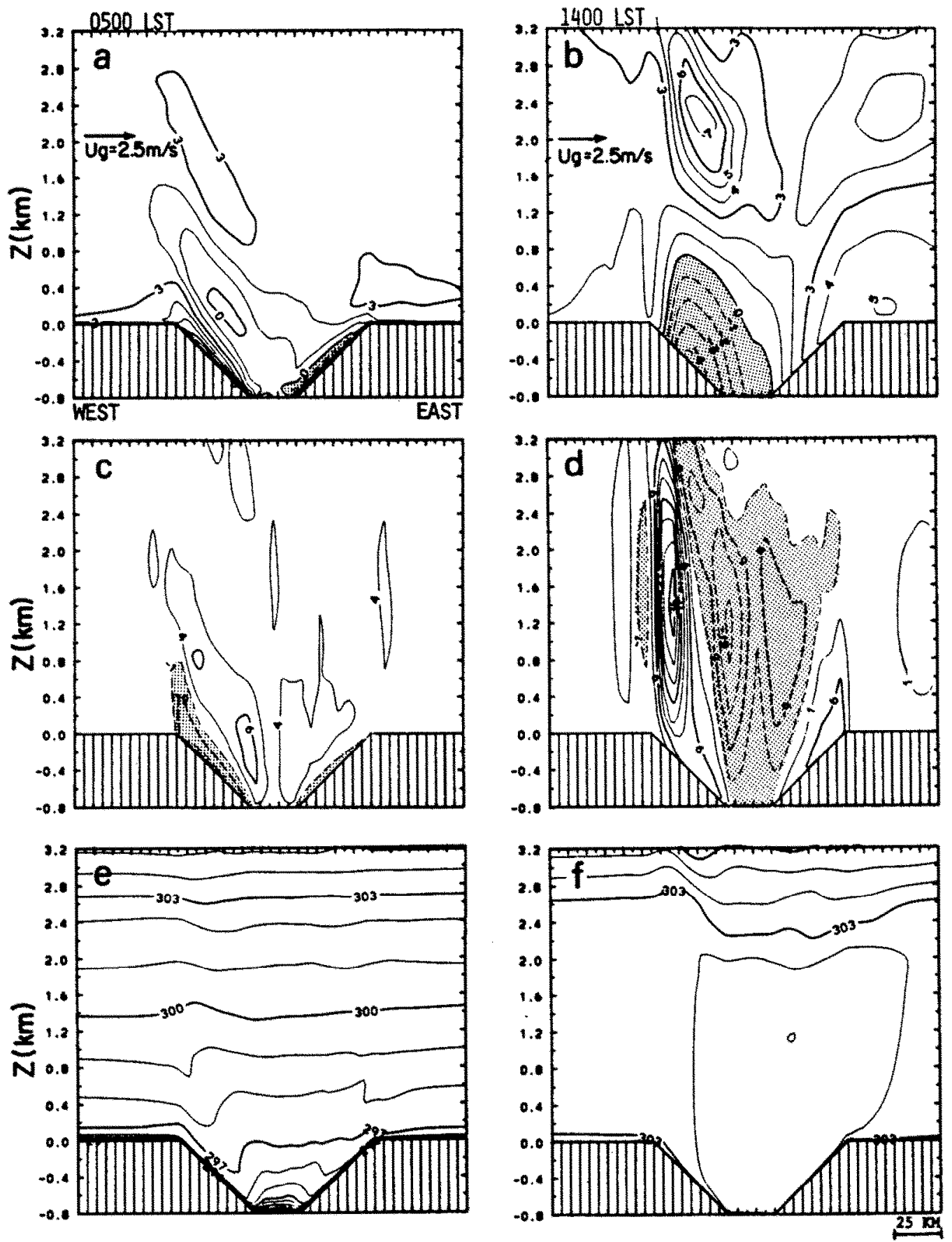

Fig. 2. Representative meteorological fields for the cross-valley transport cases (westerly synoptic flow) for nighttime (0500 LST), and for daytime (1400 LST), summer case; (a) and (b) $u$ component of the wind (cross valley) given in $\mathrm{m} \mathrm{s}^{-1}$; dashed contours (shaded) indicate negative values of $u$ (i.e. easterly flow); (c) and (d) vertical velocities given in $\mathrm{cm} \mathrm{s}^{-1}$; dashed contours (shaded) indicate negative values of vertical velocities (i.e. subsidence); (e) and (f) potential temperature $(\mathrm{K})$.

LST cross-valley wind and vertical velocity components, respectively, which are somewhat more intense compared to the corresponding winter case pattern. The drainage flow during the summer in these simulations is slightly more intense as compared to the winter case. The potential temperature pattern at 0500 LST (Fig. 3e) resembles that of the winter case.
At 1400 LST (Figs $2 b, 2 d$ and $2 f$ ) there exists a qualitative similarity to the meteorological fields obtained in the corresponding winter case; however, the intensities of the thermally induced flows, the vertical velocity at the convergence zone, the depth of the mixing layer and the turbulence are greater as the sensible heat fuxes in this season are more intense. 


\subsection{Transport patterns - valley case}

a. Winter case. In case 1 (see Table 2) the initial location of the polluted mass (with a depth of $320 \mathrm{~m}$ and a horizontal size of $15 \mathrm{~km}$ ) is indicated in Fig. $3 \mathrm{a}$. It is differentiated graphically into three layers (bottom layer, $\alpha$, middle layer, $\beta$; upper layer, $\gamma$ ). By 1400 LST the mass (Fig. 3b) is located along the western slope, and is well mixed to a depth of about $1 \mathrm{~km}$. During that period of the day the opposing upslope flows are at their peak, so that the transport is slowed. As the nocturnal drainage becomes established, the shallow and thermally stable drainage flow affects the bottom of the mass (Fig. 3c). However, as a result of weak turbulence in that layer, the mass is mostly transported above the lower elevation of the valley by the dominant synoptic fow at higher elevations (i.e. separation of flows) (Fig. 3c). By 0500 LST, $24 \mathrm{~h}$ following the release (Fig. 3d), it is evident that the major portion of the mass was transported above the valley, while only a small portion was affected by the nocturnal drainage circulation, and was thus trapped within the valley bottom.

A release at 2100 LST (case 2) is affected during the

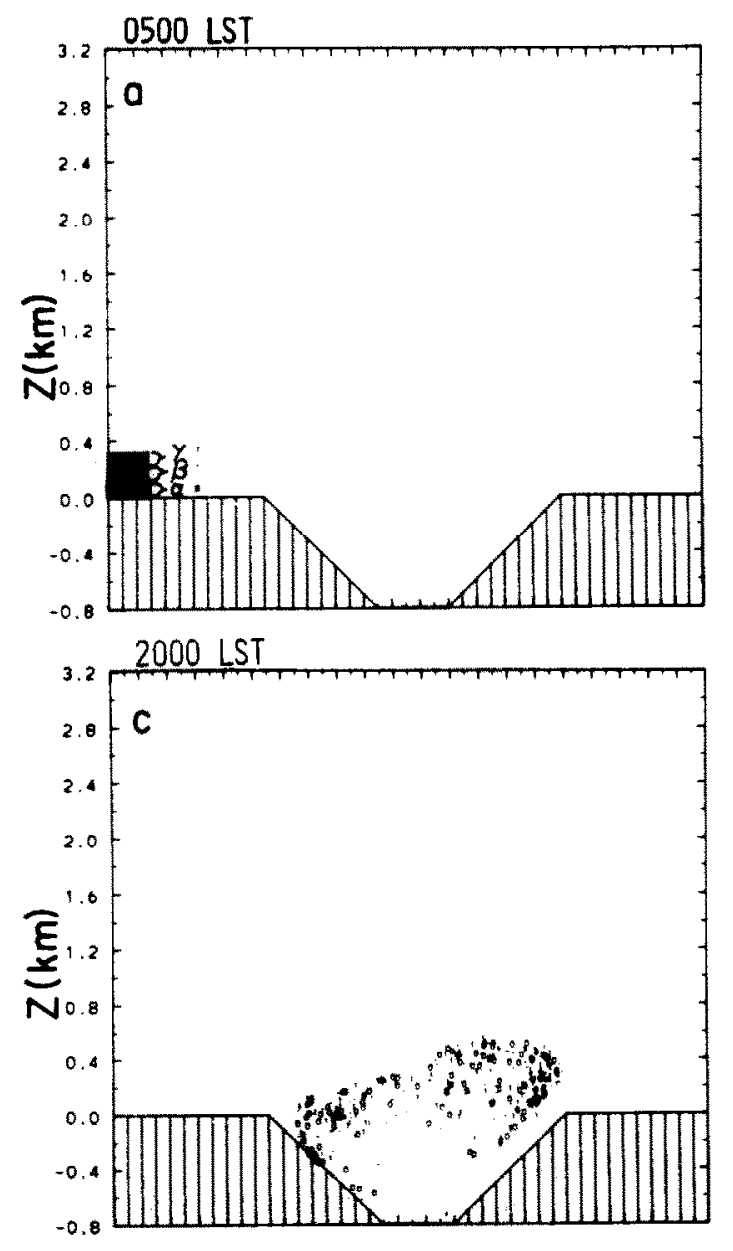

nocturnal period by a vertical shear of the horizontal wind as the drainage flow coupling with the synoptic flow is more pronounced within the surface layer (Fig. 4a). By 0300 LST the mass was advected to the west slope, with turbulence evident in the mixing of the previously horizontally homogeneous layers of particles. The bottom layer $(\alpha)$ which was at the leading edge of the mass over the flat terrain is, in the new rearrangement, at the edge of the mass, while the top layer $(y)$ is primarily at the back end of the mass. At noon (Fig. 4c), the mass is well mixed vertically within the PBL which has a similar depth to the valley. By 2100 LST (Fig. 4d) the particles have become well mixed within the valley as a result of the daytime turbulence and the beginning of the nocturnal drainage effect. Particles above the valley depth have been advected out of the valley by the synoptic flow.

b. Summer case. Daytime upslopes and mixing depth are more pronounced in the summer cases, as compared to the winter case; thus a different impact on transport is expected. The initial depth of the pollutant mass for the summer case (Fig. 5a; case 3) is larger $(620 \mathrm{~m})$ compared to the winter case since the mixing

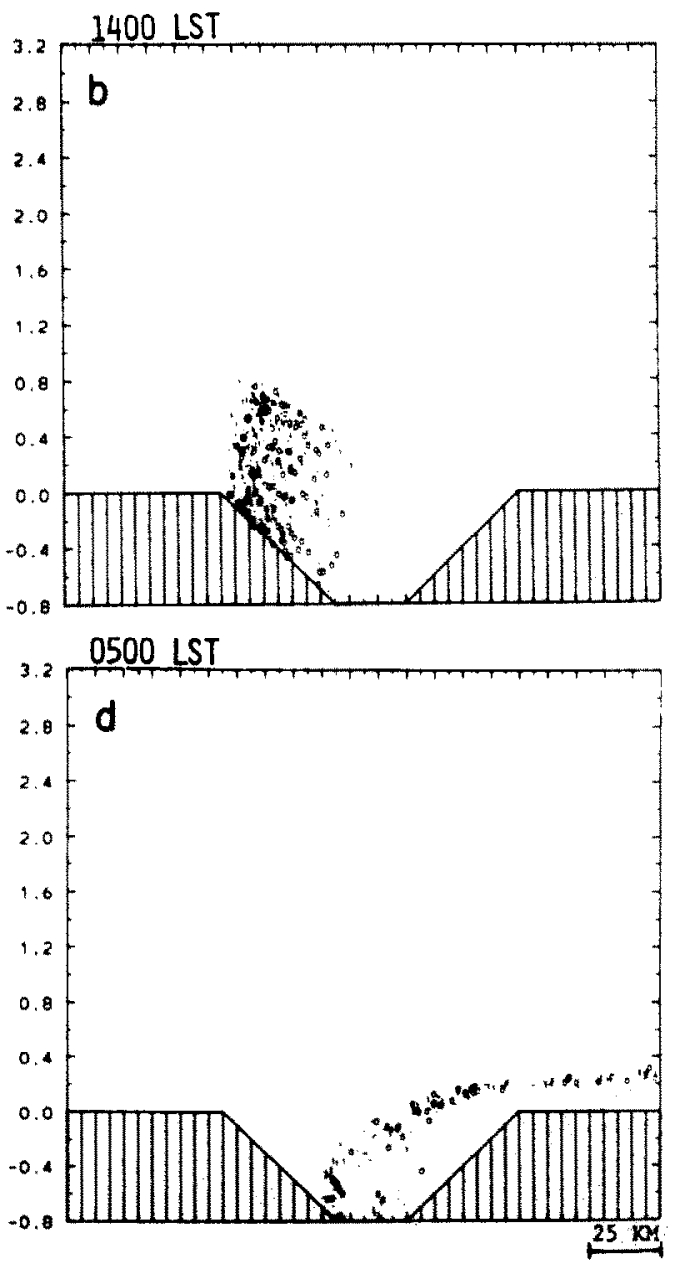

Fig. 3. Features of pollutant particles dispersion at several selected hours (case 1). 

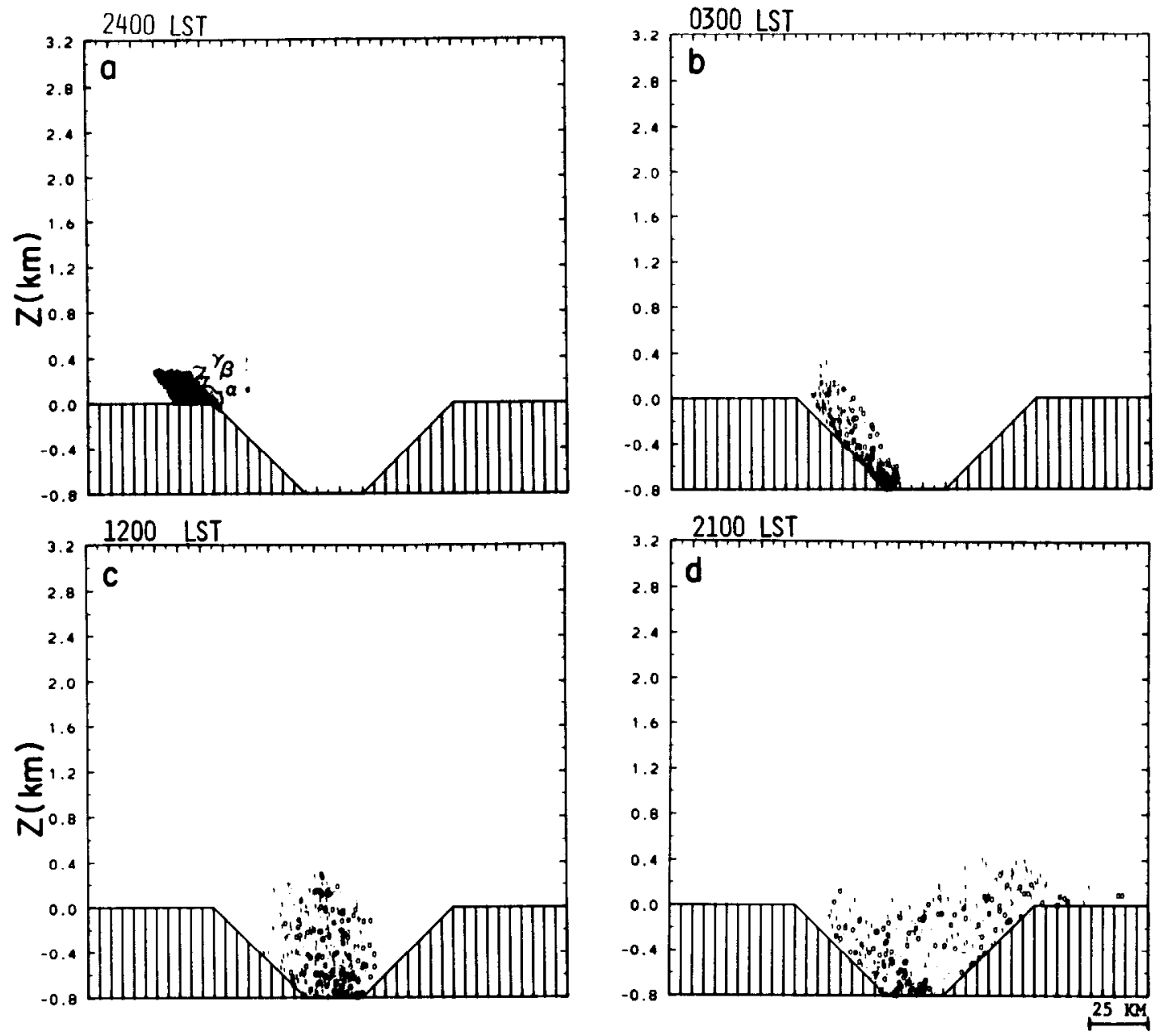

Fig. 4. Features of pollutant particles dispersion at several selected hours (case 2).

layer (in which the initial pollutant mass is assumed to be confined) is typically deeper in the summer. By 1400 LST (Fig. 5b), in addition to the deep mixing, the development of two vertical branches of particles is simulated: the left-hand side reflects upward venting at the convergence zone between the synoptic and upslope flows; the right-hand one is due to the sinking by the downward vertical velocities within the middle of the valley. [Such daytime sinking in the valley center is confirmed by observations and is thought to have a major impact on the dissipation of nocturnal inversions in valleys (Whiteman and McKee, 1978)]. The separate branches largely disappeared by 1700 (Fig. 5c) as the mass generally advected eastward and mixed further. During the nocturnal period above the valley height, the pollution is advected out of the domain as the downslope drainage wind circulation is shallow. The drainage flow coupled with the synoptic flow clears the particles from the west side of the slope as shown for 0500 LST (Fig. 5d) which reflects the end of the nocturnal flow. Compared to the equivalent winter case (case 1), during the summer mixing is deeper, thereby providing a mechanism for advection out of the valley for a large portion of the particles, although during the night, a portion is trapped within the valley as the boundary layer stabilizes.

Changing the time of release to 2100 LST (case 4) causes the particles to be advected into the valley during the night. The $\alpha$ particles affected by the drainage flow are in front, with the $\gamma$ particles lagging aloft (Fig. 6a). As a result, in the morning the particles in the middle of the valley become mixed vertically, with the $\alpha$ and $\beta$ particles in the front of the mass and the $\gamma$ particles in the back edge of the mass (Fig. 6b). As the daytime upslope developed, particles were advected along both slopes (Fig. 6c). In the evening as the nocturnal circulations become re-established, the eastern slope particles tend to be advected out of the eastern boundary, while the rest tend to be trapped in the valley for the night.

\subsection{Meteorological fields-ridge case}

a. Winter case. Figures $7 \mathrm{a}, 7 \mathrm{c}$ and $7 \mathrm{f}$ present the nocturnal period peak patterns of the meteorological fields for the winter flow over the ridge illustrated in the figure (0500 LST). A significant intensification of the 

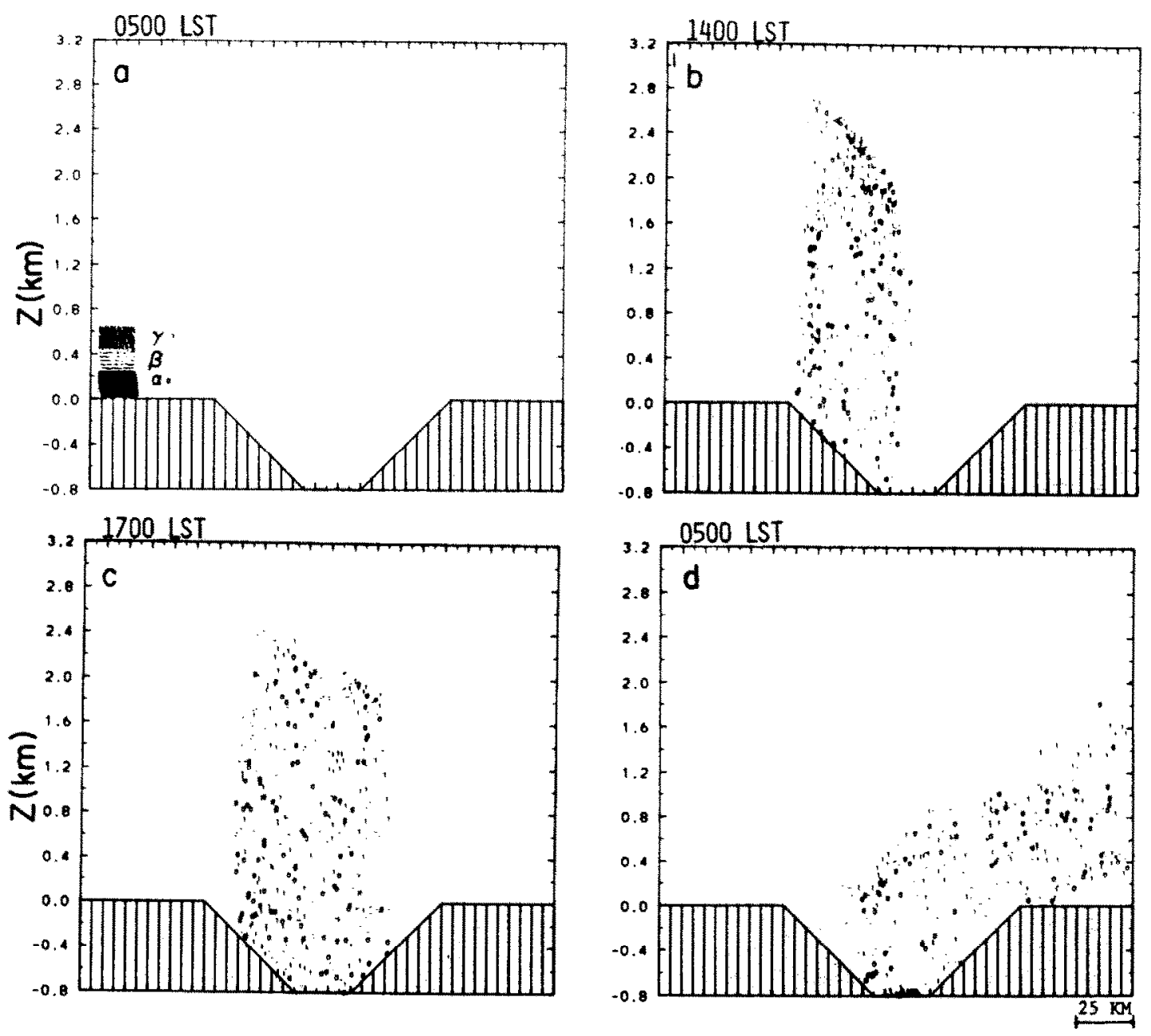

Fig. 5. Features of pollutant particles dispersion at several selected hours (case 3).

flow from the synoptic wind resulted by that hour, as a result of the forced ascent over the ridge, in the stable background thermal stratification; Fig. 7a. Shallow drainage flow along the western slope is also noticeable, with strong downward vertical velocities over the eastern slope. A shallow surface nocturnal inversion is predicted in the simulated domain (Fig. 7e). This is in addition to the stabilization along the east slope of the lower atmosphere involved with the contraction of the flow passing the ridge top.

By 1400 LST the intense downward flow along the east slope had diminished as a neutral stratification developed in the lower atmosphere (Fig. 7b). The daytime upslope flow along this slope was shifted toward the flat terrain region; the related convergence is reflected there by the upward cell of vertical velocities. Therefore, the PBL along the west slope is considerably shallower than that along the eastern slope, as evident from the thermal stratification structure (see Fig. 7f).

b. Summer case. The meteorological fields reflecting the nocturnal period during the summer with a synoptic fiow of $2.5 \mathrm{~m} \mathrm{~s}^{-1}$ are shown in Fig. 8. Drainage flow is evident along both slopes, with the western slope consisting of a shallow layer (indicated by the dashed contours), while the eastern slope is coupled with the flow which has been intensified dynamically as it crossed the ridge. The resultant surface wind speeds along the eastern slope reach a peak of around $10 \mathrm{~m} \mathrm{~s}^{-1}$ (Fig. 8a). The vertical velocity pattern (Fig. 8c) consists of downward vertical velocities along both slopes. The nocturnal surface inversion is relatively shallow but intense along the lower terrain of the simulated domain where the surface wind speeds are relatively low (Fig: 8e).

The daytime mesoscale meteorological fields are presented for 1400 LST in Figs 8b, 8d and 8f. The upslope flow along the western side of the ridge is supported by the synoptic flow, and penetrates to the lee side of the ridge where it converges with the thermally-forced eastern upslope flow. An intensifcation of the westerly flow is associated with the return flow computed aloft in the upper layers of the PBL above the eastern slope (Fig. 8b). The convergence zone along the eastern slope generates intense vertical velocities with peak values of above $50 \mathrm{~cm} \mathrm{~s}^{-1}$ by this 

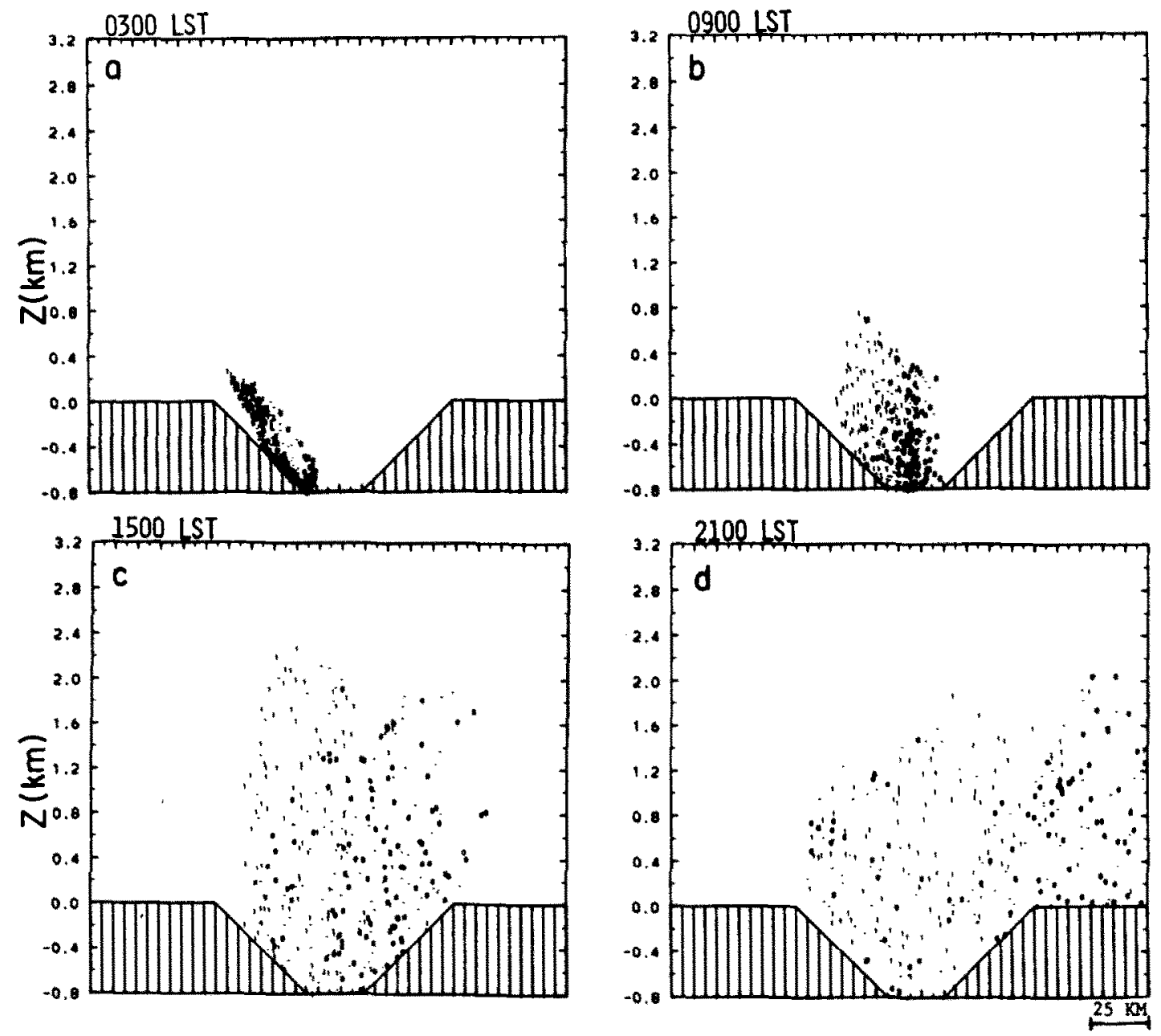

Fig. 6. Features of pollutant particles dispersion at several selected hours (case 4).

hour (Fig. 8d). The strong surface heating during the daytime in summer leads to the development of a relatively deep mixing layer, as evident from the potential temperature field shown in Fig. 8f. The vertically oriented potential temperature contours illustrate the thermally neutral stratification associated with the PBL. It is also worth noting the relatively deeper PBL depth within the convergence zone along the eastern slope, which resulted from the strong upward vertical velocities in that location.

\subsection{Transport patterns-ridge case}

a. Winter case. The initial position of the polluted air mass for case 5 where the release is at 0500 LST is provided in Fig. 9a. The advection of the mass in the early hours of the winter morning is associated with a vertical shear of the horizontal wind and a lack of deep turbulence (Fig. 9b). As the PBL develops in the morning and reaches the top of the simulated pollution mass, the PBL turbulence causes a well mixed layer vertically, but the horizontal distribution of the particles is non-uniform. The horizontal differenti- ation between the $\alpha, \beta$ and $\gamma$ particles is quite noticeable (Fig. 9c). This distribution of particles resulted because the vertical shear of the horizontal wind (before the strong mixing developed) caused the top layer particles $\gamma$ to be located at the front of the polluted mass, while the bottom layer particles $(\alpha)$ are in the back. This configuration is still observed at $1700 \mathrm{LST}$, as the mass continues to be advected along the slope, despite increased vertical mixing.

Case 6 involves a 2100 LST release. As a result of the weak turbulence and the existence of wind shear during the night in the lower atmosphere (see Fig. 7a), the mass is stretched horizontally as it is transported toward the ridge (Fig. 10a). At 0900 LST the $\gamma$ layer particles are advected downward along the east slope where the strong slope wind has not yet diminished entirely, while the $\alpha$ layer particles are lagging along the west slope. Vertical mixing by turbulence is evidently involved with an advection of the mass out of the domain with continued vertical mixing noted at 1500 LST (Fig. 10c). By 2100 LST essentially only the initial lower layer of particles $(\alpha)$ remains within the simulated domain. 

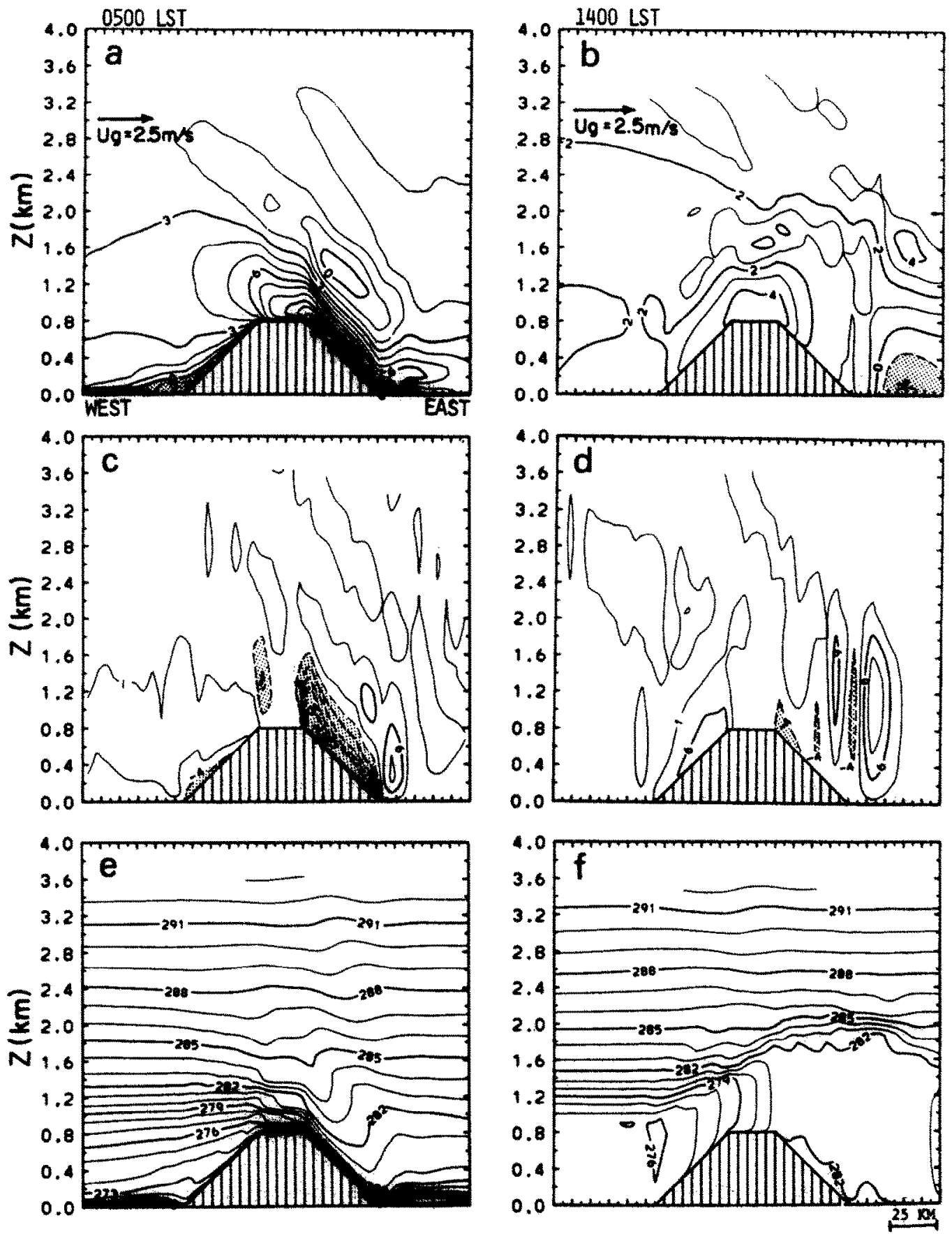

Fig. 7. Representative meteorological fields for the cross-ridge transport cases (westerly synoptic flow) for nighttime (0500 LST), and for daytime (1400 LST), winter case; (a) and (b) $u$ component of the wind (cross valley) given in $\mathrm{m} \mathrm{s}^{-1}$; dashed contours (shaded) indicate negative values of $u$ (i.e. easterly flow); (c) and (d) vertical velocities given in $\mathrm{cm} \mathrm{s}^{-1}$; dashed contours (shaded) indicate negative values of vertical velocities (i.e. subsidence): (e) and (f) potential temperature $(\mathbf{K})$.

b. Summer case. Figure 11 presents the features involved with a summer release at 0500 LST (case 7). During the day, as the PBL is more developed and the slope circulation becomes more intense as compared to the winter case, the dispersion features are enhanced (e.g. for 1700 LST compare Fig. 11b for the summer case with Fig. $9 \mathrm{~d}$ for the winter). The opposing upslope flow on the eastern slope, and the location of a horizontal wind convergence zone there, led in the later hours to the transport of the pollutants aloft (i.e. venting) in that region, as evident from Figs $11 \mathrm{c}-\mathrm{d}$.

Finally, a release at 2100 LST is presented (Fig. 12). During the nocturnal period, in the absence of signifi. cant turbulence and with downslope nocturnal flow in 

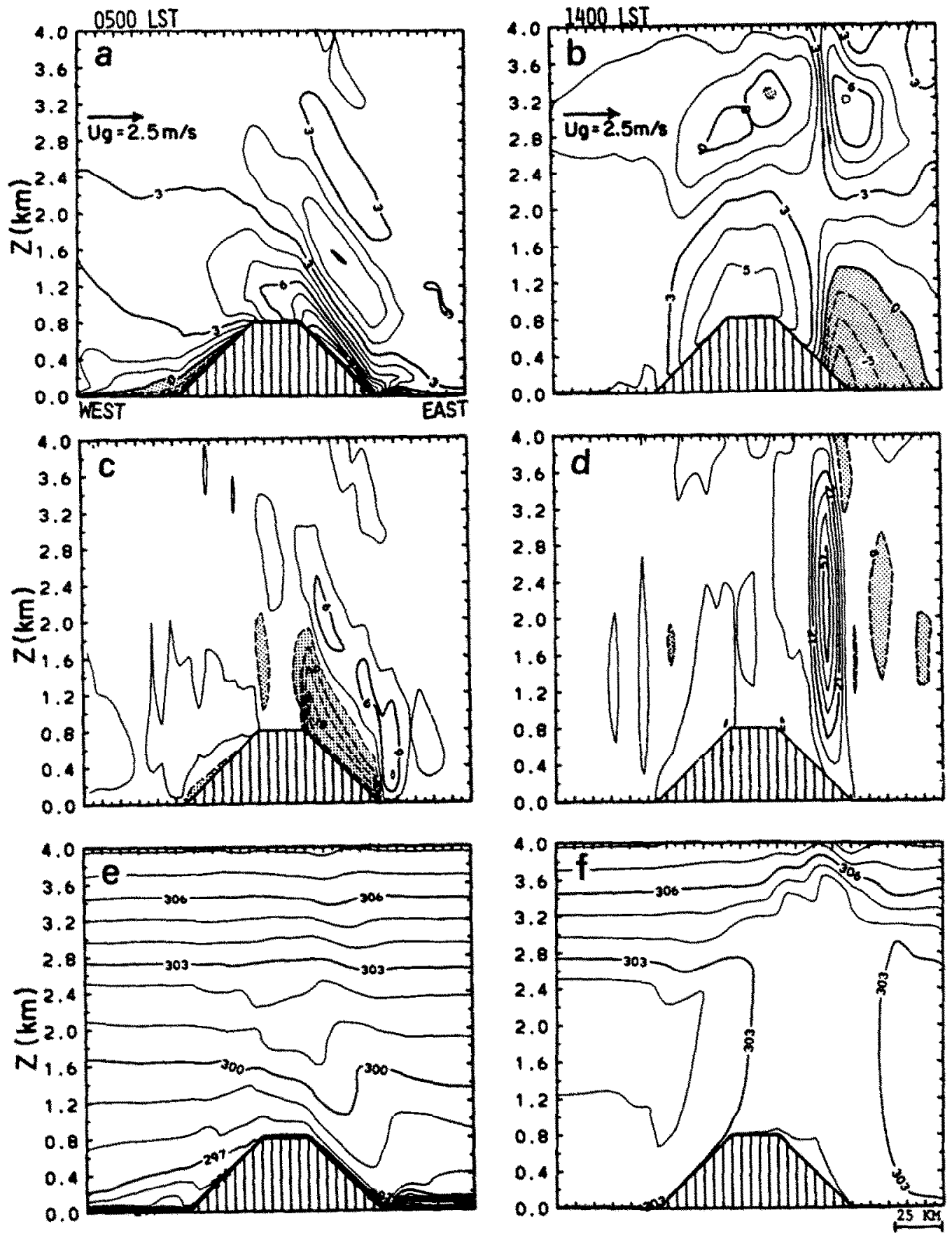

Fig. 8. Representative meteorological fields for the cross-ridge transport cases (westerly synoptic flow) for nighttime (0500 LST), and for daytime (1400 LST), summer case; (a) and (b) $u$ component of the wind (cross valley) given in $\mathrm{m} \mathrm{s}^{-1}$; dashed contours (shaded) indicate negative values of $u$ (i.e. easterly flow); (c) and (d) vertical velocities given in $\mathrm{cm} \mathrm{s}^{-1}$; dashed contours (shaded) indicate negative values of vertical velocities (i.e. subsidence); (c) and (f) potential temperature $(\mathbf{K})$.

the low elevation replaced by eastward synoptic flow aloft, a horizontal spread of the particles by the differential vertical profile of the horizontal wind is expected. Figure 12a illustrates that the $\alpha$ particles lagged above the lower western slope, while the $y$ particles reached the ridge top by 0600 LST. At 0900 LST as vertical convective mixing began to take place, the horizontal differentiation between the $\alpha, \beta$ and $\gamma$ particles remained well defined. The daytime convergence zone which developed along the western slope caused an upward venting of pollutants, which being transported to above the upslope wind layer, were then advected westward by the dominating synoptic flow (Figs 120-d). Note that during these processes the spatial differentiation between the $\alpha, \beta$ and $\gamma$ particles remained. 

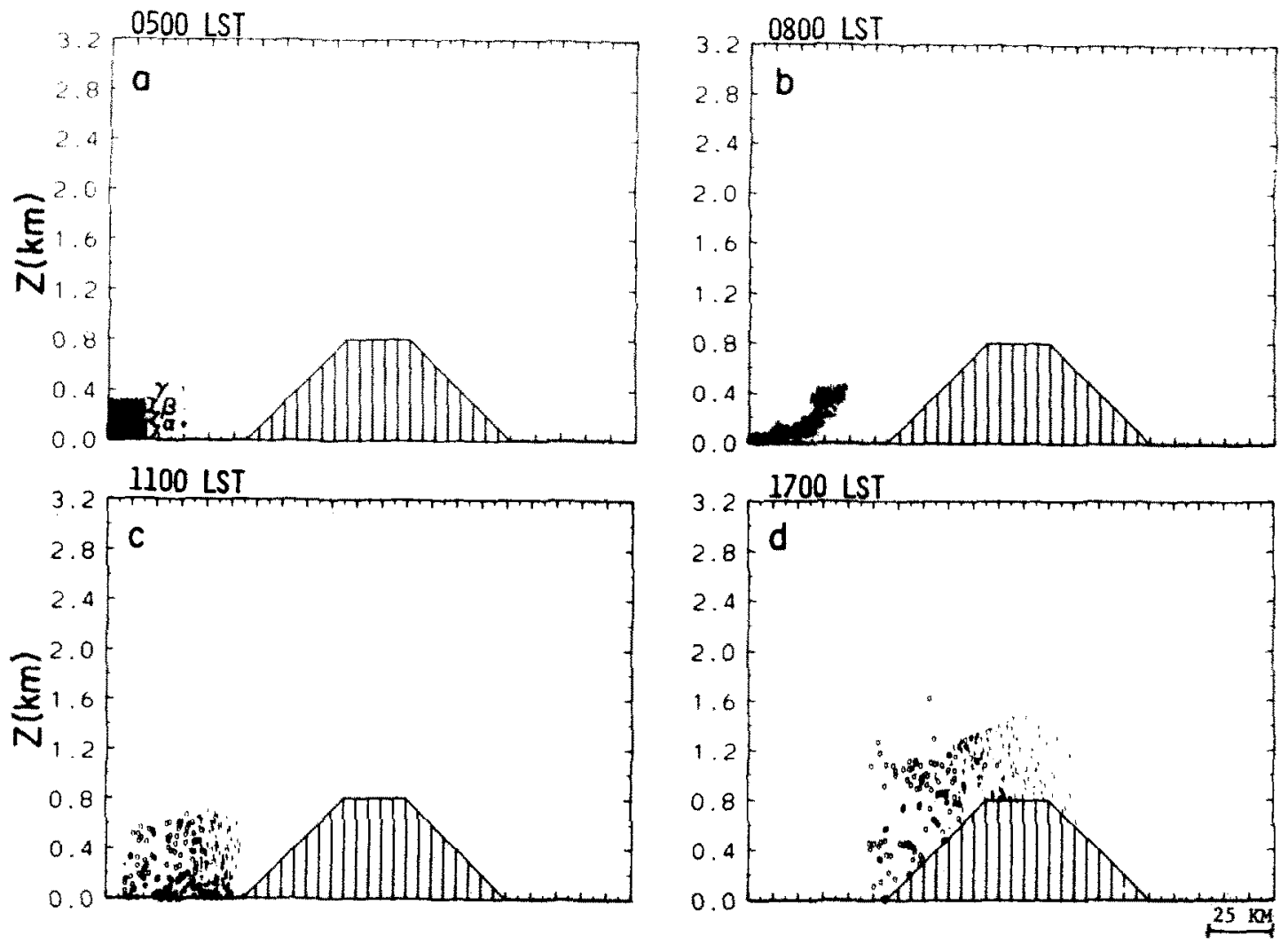

Fig. 9. Features of pollutant particles dispersion at several selected hours (case 5).
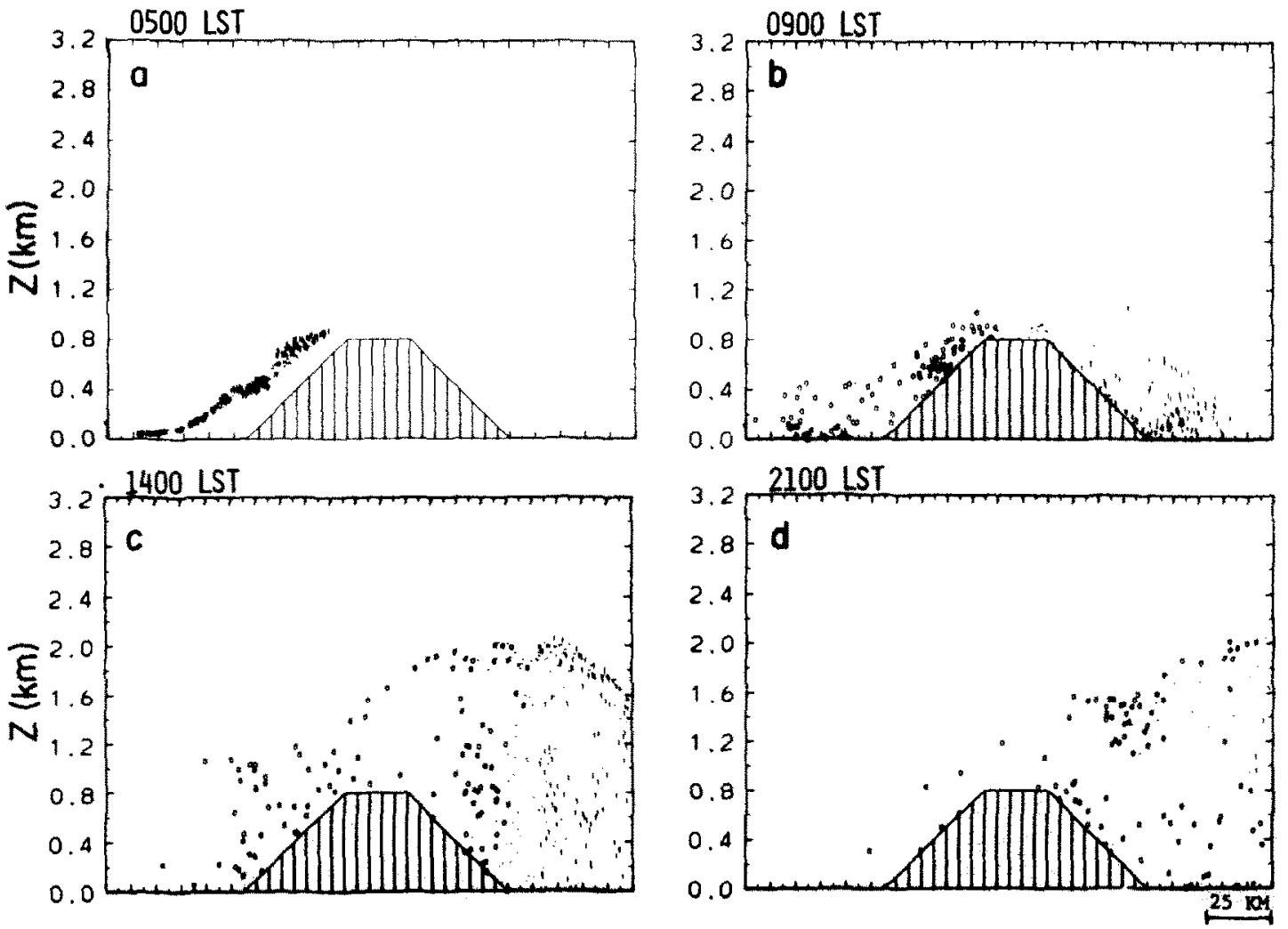

Fig. 10. Features of pollutant particles dispersion at several selected hours (case 6). 

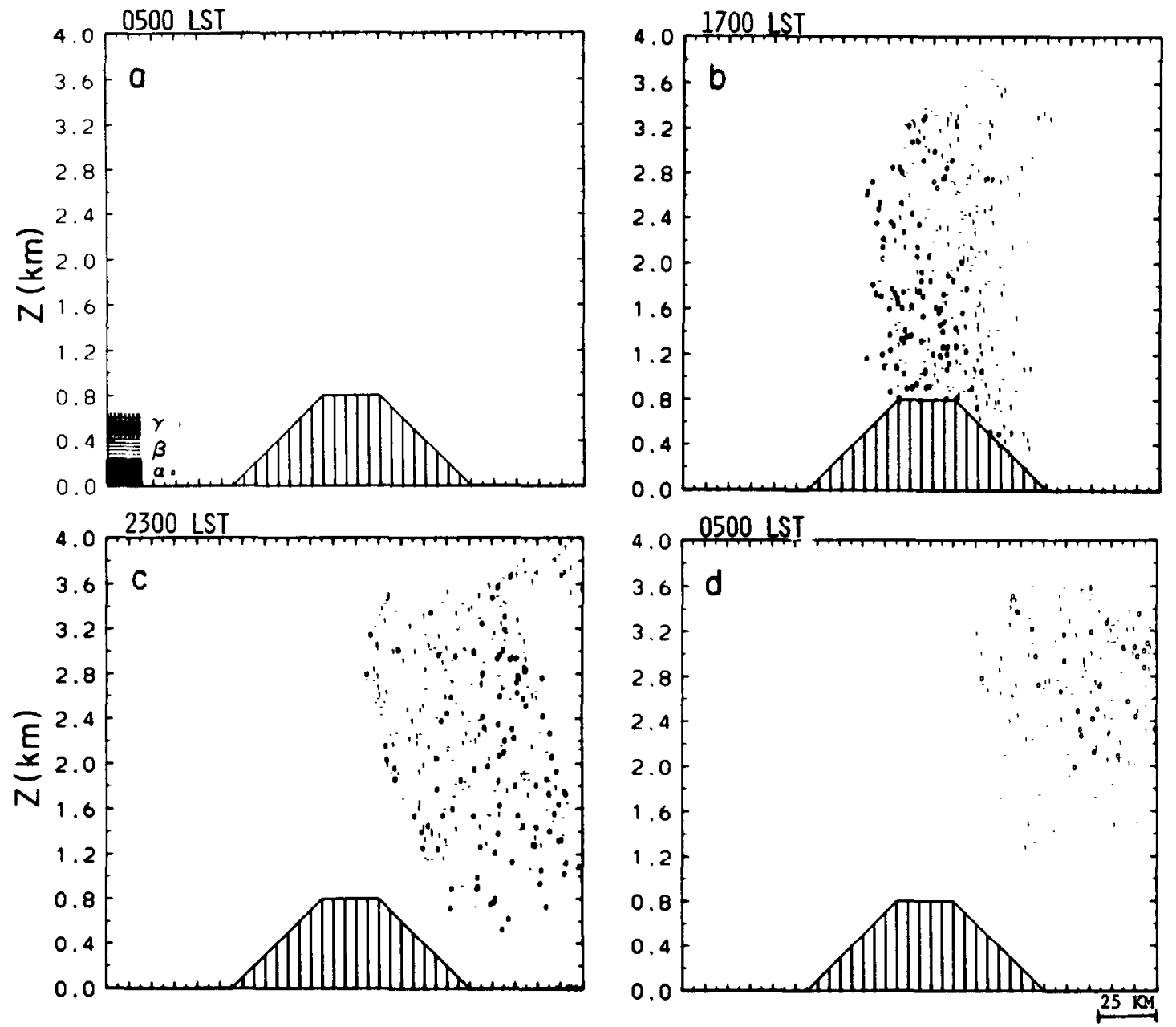

Fig. 11. Features of pollutant particles dispersion at several selected hours (case 7).

\section{DISCUSSION AND GENERAL EVALUATIONS OF VALLEY/RIDGE IMPACT ON REGIONAL. TRANSPORT}

In this section additional evaluations are provided as to the impact of valley/ridge circulations on regional scale transport under generalized conditions. As evaluated in the previous section, the timing of arrival of a polluted volume of air to the location of the valley/ridge circulation is critical in the determination of the subsequent transport features. The typical regional pollutant transport to such an area can be viewed as a continuous passage of such volumes of pollution (with their vertical extent determined by the daytime mixing layer depth). Hence the overall impact of the valley/ridge structures on regional transport can be projected by interpreting the impact on several representative volumes of air while also considering the non-steady characteristics of related mesoscale meteorological fields. Based on the simulation results, it is suggested that in the presence of a directionally sheared ambient synoptic flow with height, venting upwards of the pollutant in the mesoscale convergence zones as illustrated in some of the simulations could also cause changes in the general direction of the transport.

When polluted air masses such as those considered in the present study are transported under the same ambient synoptic conditions, but over uniform flat terrain, the following main features are expected: steady transport (with the synoptic flow intensity of $2.5 \mathrm{~m} \mathrm{~s}^{-1}$ in the present study) with the pollutant air mass somewhat extended by diffusion laterally with time, as well as extended vertically with the daytime growth of the PBL. The simulated cases in our study illustrate the extent that the non-uniform terrain results in more complex transport patterns, as a result of the substantial spread of the pollutant particles by the spatially non-uniform wind field and its temporal variations. Additionally the study provides evaluations as to the significance of the local accelerations and decelerations of the transport caused by thermallyforced mesoscale flow.

The present study focused on terrain with 2-D symmetry. This situation can be regarded as realistic for many real world topographical features. Obviously when 2-D symmetry cannot be considered, a distortion 

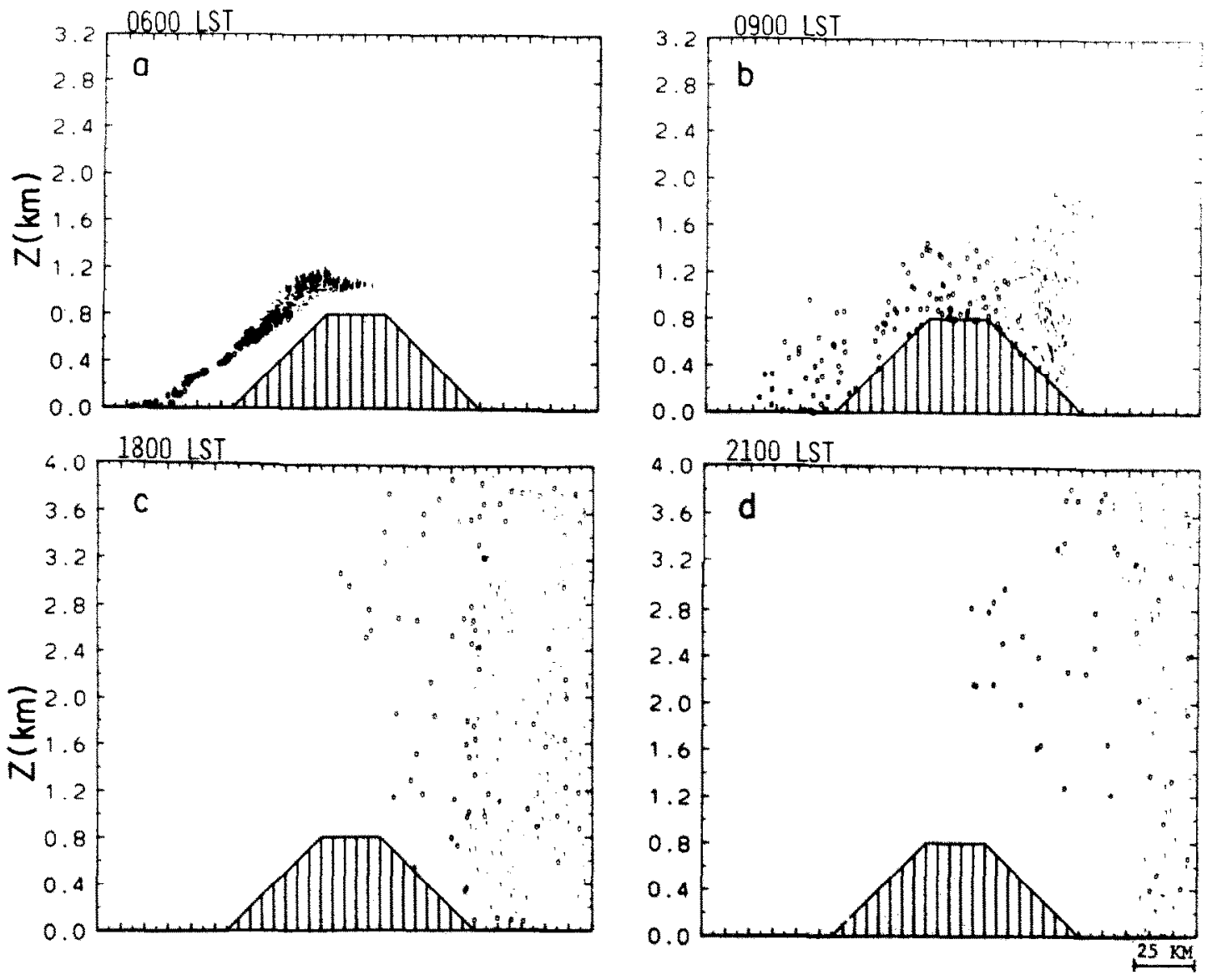

Fig. 12. Features of pollutant particles dispersion at several selected hours (case 8).

of the features obtained in the present study is to be expected. However, the features involved with the fundamental physical processes illustrated in the 2-D cases presented in this study should be retained also in 3-D structured terrain.

The following qualitative evaluations are suggested in order to generalize the situations simulated in the present study. The evaluations are based on widely accepted physical concepts relating to flow in complex terrain.

\section{(a) Valley/ridge aspect ratio effects}

Generally, a larger aspect (ratio of typical valley/ridge depth to its typical width) tends to intensify both the daytime and night-time induced thermal flows. Therefore, with an increased aspect, the daytime convergence zone generated by coupled synoptic and valley flows would tend to be located in the higher elevations of the slope, and be involved with stronger upward vertical velocities. Consequently, more intense venting of pollutants to upper layers should be expected, causing a transport of the pollutants out of the valley.

\section{(b) Synoptic flow: cross-valley effects}

As the intensity of the synoptic flow increases, the daytime upslope circulation (and the convergence zone) shifts downslope (e.g. Davidson and Rao, 1963), thus the impact of the valley circulation on the modification of the regional scale transport reduces. On the other hand, as the aspect increases synoptic flow tends to be separated from the low elevation thermally induced flows (e.g. Segal et al., 1983). The direction of the synoptic flow relative to the valley is also of significant importance in the determination of the impact on the transported polluted air mass. When the synoptic flow crosses the valley perpendicularly an asymmetric interaction with the daytime valley circulation results, with an emphasized convergence zone in the front slope. When the synoptic flow is along the valley direction, the development of circulations tends to be symmetric along its bottom.

\section{(c) Synoptic flow: cross-ridge effects}

To provide a bulk evaluation of the dynamical features which are involved with flow crossing a ridge, the Froude number, $F_{\mathrm{r}}\left(F_{\mathrm{r}}=U / N h\right.$ where $U$ is the synoptic flow speed; $N$ is the Brunt Vaisala frequency, and $h$ is the ridge height), can be used (see, for example, Smith (1979) for theory and discussion of airflow over elevated terrain and Arritt et al (1987) for model evaluations). As $F$, reduces (i.e. ambient thermal stability and/or $h$ increases, or $U$ decreases) blocking of the cross ridge flow along the front slope and its 
acceleration along the lee slope become significant. On the other hand, as the thermal stratification tends to neutral and/or $h$ reduces, or if $U$ increases, the flow streamlines tend to follow the ridge relief without a significant alteration in its intensity (e.g. compare Fig. 7a and Fig. 8a which are involved with different ambient thermal stratifications).

\section{(d) PBL depth}

The depth of the daytime upslope flow layer (under light synoptic flow) is about the same as the depth of the PBL (e.g. Ye et al., 1988a), thus the PBL depth provides an indication of the impact of the valley/ridge circulation on the synoptic scale transport. Daytime development of the PBL causes downward mixing of horizontal momentum, thus suppressing the upslope flow on the lee side of a ridge, and eliminating the convergence zone in that location when the synoptic flow is vertically sheared and opposing the upslope flow (e.g. Banta, 1984, 1986). In such cases upward venting of pollutants on the lee side of a mountain is replaced by downslope transport of the pollutants. Similar situations can be assumed also in valley cases.

\section{(e) Surface characteristics}

The surface characteristics may substantially affect the generated valley/ridge circulations, mostly during the daytime hours. The sensible heat flux from the surface into the atmosphere is the driving force affecting the intensity of the valley/ridge circulation (as well as affecting the depth of the PBL). Wet and vegetated slopes tend to reduce sensible heat fluxes and the intensity of the generated circulation (e.g. Ookouchi et al., 1984). A similar effect, however much more pronounced, is expected along slopes covered by snow (e.g. Ohata et al., 1981).

\section{(f) Other influences}

Cloudiness reduces the incoming solar radiation at the surface and consequently reduces the surface sensible heat flux during the day. As a result the daytime thermally induced upslope circulations may become significantly retarded (e.g. Segal et al., 1986). Nocturnal cloudiness somewhat increases the incoming long-wave radiation at the surface (e.g. Oke, 1978) and reduces the radiative cooling due to long-wave radiation flux divergence, thus tending to suppress the drainage flow (e.g. Ye et al., 1988b). Finally, it is worth noting that heavily polluted air masses affect to some degree the radiative transfer in the atmosphere (c.g. Reck and Hummel, 1981), and thus also may have a secondary effect on the buildup of the slope circulations.

Acknowledgements-The work reported in this paper was sponsored by the Electric Power Research Institute, Inc. (EPRI) under Contract No. RP-1630-53, by the National Park Service under Contract NA81RAH00001, and by the Army Research Office under Contract DALL03-86-K-0175. Computer calculations were made at the National Center for Atmospheric Research (NCAR). NCAR is sponsored by the
National Science Foundation. Linda Jensen and Sandra Wittler capably carried out the typing and preparation of the manuscript.

\section{REFERENCES}

Abbs D. J. (1986) Sea breeze interaction along concave coastline in southern Australia: observation and numerical model study. Mon. Wea. Rev. 114, 831-848.

Arritt R. W. (1985) Numerical studies of thermally and mechanically forced circulations over complex terrain. Ph.D. dissertation, Department of Atmospheric Science Colorado State University, Fort Collins, $\mathrm{CO}$.

Arritt R. W., McNider R. T. and Pielke R. A. (1987) Numerical model evaluation of the extension of the critical dividing streamline hypothesis to mesoscale two-dimensional terrain. Atmospheric Environment 21, 1905-1913.

Artz R., Pielke R. A. and Galloway J. (1985) Comparison of the ARL/ATAD constant level and the NCAR isentropic trajectory analyses for selected case studies. Atmospheric Environment 19, 47-63.

Banta R. M. (1984) Daytime boundary-layer evolution over mountainous terrain-1. Observations of the dry circulation. Mon. Wea. Rev. 112, 340-356.

Banta R. M. (1986) Daytime boundary layer evolution over mountainous terrain-II. Numerical studies of upslope flow duration. Mon. Wea. Rev. 114, 1113-1130.

Bhumralkar C. and Teasley J. I. (eds) (1984) Meteorological Aspects of Acid Rain, Acid Precipitation Series, Vol. 1. Butterworth, Stoncholm, MD.

Blackadar A. K. (1978) High resolution models of the planetary boundary layer. Adv. Envir. Sci. Engr. 1, 50-85.

Davidson B. and Rao P. K. (1963) Experimental studies of the valley-plain wind. Air Water Pollut. 7, 907-921.

Eliassen A. (1980) A review of long range transport modeling. J. appl. Met. 19, 231-240.

Haagenson P. and Shapiro M. A. (1979) Isentropic trajectories for derivation of objective analyzed meteorological parameters. NCAR Tech. Note, NCAR/TN-149-STR Atmospheric Quality Division, NCAR, Boulder, CO.

Heffter J. L. (1980) Air Resources Laboratories atmospheric transport and dispersion model (ARL-ATAD). NOAA Technical Memorandum ERL-ARL-81.

Henmi T. H. and Bresch J. F. (1985) Meteorological case studies of regional high sulfur episodes in the western United States. Atmospheric Environment 19, 1783-1796.

Kaimal J. C., Wyngaard J. C., Haugen D. A., Cote O. R., Izumi Y., Caughey S. J. and Readings C. J. (1976) Turbulence structure in the convective boundary layer, J. atmos. Sci. 33, 2152-2168.

Legg B. J. and Raupach M. R. (1982) Markov-chain simulations of particle dispersion in inhomogeneous flows: the mean drift velocity induced by a gradient in Eulerian velocity variance. Boundary-Layer Met. 24, 3-13.

Mahrer Y. and Pielke R. A. (1977) A numerical study of the air flow over irregular terrain. Contr. atmos. Phys. 50, 98-113.

McNider R. T. (1981) Investigation of the impact of topographic circulations on the transport and dispersion of air pollutants. Ph.D. dissertation, University of Virginia, Charlottesville, VA.

McNider R. T., Hanna S. R. and Pielke R. A. (1980) Subgrid scale plume dispersion in coarse resolution mesoscale models. Proceedings 2nd Jt, Am. Met. Soc./Air Pollut. Control Ass. Conf,; Appl. Air Pollut. Met., pp. 424-429.

McNider R. T., Moran M. D. and Pielke R. A. (1988) Influence of diurnal and inertial boundary layer oscillations on long-range dispersion. Atmospheric Environment (submitted).

McNider R. T. and Pielke R. A. (1981) Diurnal boundary layer development over sloping terrain. $J_{*}$ atmos. Sci. 38, 2198-2212.

McNider R. T. and Pielke R. A. (1984) Numerical simulation 
of slope and mountain flows. J. clim. appl. Met. 23, $1441-1453$

Ohata I., Higuchi K. and Ikegami K. (1981) Mountain-valley wind system in Khumber Himal, East Nepal. J. Met., Japan 59, 753762 .

Oke J. R. (1978) Boundary Layer Climates. Methuen, London.

Ookouchi Y.. Segal M., Kessler R. C. and Pielke R. A. (1984) Evaluation of soil moisture effects on the generation and modification of mesoscale circulations. Mon. Wea. Rev. $112,2281-2292$.

Panofsky H. A., Lenschow D. H. and Wyngaard J. C. (1977) The characteristics of turbulent velocity components in the surface layer under convective conditions. Boundary-Layer Met. 11, 355-361.

Pielke R. A. (1974) A three-dimensional numerical model of sea breezes over south Florida. Mon. Wea. Rev. 102, 115-139.

Pieike R. A. (1984) Mesoscale Meteorological Modeling. Academic Press, Orlando, FL.

Pielke R. A., McNider R. T., Segal M. and Mahrer Y. (1983) The use of a mesoscale numerical model for evaluations of pollutants transport and diffusion in coastal regions and over irregular terrain. Bull. Am. Met. Soc. 641, 243-249.

Reck R. A. and Hummel J. R. (1981) Influence of optical properties on surface temperatures computed with a radiative-convective model. Atmospheric Environment 15, $1727 \cdots 1731$

Samson P. J. (1980) Trajectory analysis of summertime sulfate concentrations in the northeastern United States. $J$. appl. Met. 19, 1382-1394.

Segal M., Mahrer Y. and Pielke R. A. (1982) Application of a numerical mesoscale model for the evaluation of seasonal persistent regional climatological flows. J. uppl. Met. 2I, $1754-1762$.

Segal M., Mahrer Y. and Pielke R. A. (1983) A study of meteorological patterns associated with lake confined by mountains-the Dead Sea case. $Q$. Jl R. met. Soc. 109. $549-564$.

Segal M., Purdom J. F. W., Pielke R. A., Mahrer Y. and Song J. L. (1986) Evaluation of cloud shading effects on the generation and modification of mesoscale circulations. Mon. Wea. Rev. 114, $1201 \cdot 1212$

Smith R. B. (1979) The influence of mountains on the atmosphere. Adv. Geophys. 21, 87-230.

Warner T. T., Fizz R. R, and Seaman N. L. (1983) A comparison of two types of atmospheric transport models - use of observed winds versus dynamically predicted winds. J. clim. appl. Met. 22, 394406.

Wolff G. T., Lioy P. J., Wight G. D., Meyers R. F. and Cederwall R. T. (1977) An investigation of long-range transport of ozone across the midwestern and eastern United States. Atmospheric Environment 11, 797-802.

Whiteman C. D. and McKee T. B. (1978) Air pollution implication of descent in mountain valleys. Atmospheric Environment 12, 2151-2158.

Ye Z., Segal M. and Pielke R. A. (1988a) On the impact of thermal stability and slope steepness on the development of daytime thermally-induced upslope flow. J. atmos. Sci. (in press).

Ye Z., Segal M. and Pielke R. A. (1988b) On the impact of cloudiness and atmospheric moisture on the characteristics of the nocturnal induced downslope flows. J. atmos. Sci. (to be submitted). 